IGUSABDER, 14 (2021): 336-350

\title{
Abdominal Cerrahi Sonrasında Bağırsak Fonksiyonlarını Artırmada Farmakolojik Olmayan Yöntemlerin Kullanımı: Kanitlar Ne Diyor?
}

\author{
Burçin IRMAK ${ }^{*}$, Hülya BULUT ${ }^{* *}$
}

\section{$\ddot{\mathbf{O} z}$}

Günümüzde abdominal cerrahi sonrasında hastaların sıklıkla karşılaştığı sorunlardan biri gastrointestinal motilitede fonksiyon bozukluğudur. Hastalarda gaz çlkaramama, bă̆ırsak hareketinin olmaması, karın ağrısı, distansiyon, bulantı, kusma, konstipasyon gibi belirti ve bulgularla ortaya çıkmaktadır. Bu semptomların erken sürede kontrol altına alınmaması hastalarda sıvı-elektrolit dengesizliği, iyileşmede gecikme, konforda azalma, hastanede yatış süresinde uzama, hastane kaynaklı enfeksiyon riskinin artması gibi ilave sorunlara neden olmaktadır. Ameliyat sonrası dönemde bağırsak motilitesini artırmada hem farmakolojik hem de farmakolojik olmayan tedavi yöntemleri kullanılmaktadır. Literatürde erken mobilizasyon, sakız çiğneme, erken oral hidrasyon (su, llık su, çay, kahve tüketimi), sıcak uygulama gibi farmakolojik olmayan yöntemlerin bağırsak motilitesini arttırmada etkili olduğu yer almaktadır. Bu yöntemler ucuz olması, kolay uygulanabilmesi, ilaç yan etkilerini önlemesi, olumsuz etkilerinin olmaması gibi nedenlerle tercih edilmektedir. $\mathrm{Bu}$ derlemede, abdominal cerrahi sonrasında hastalarm bağırsak motilitesini arttırmada kullanılan farmakolojik olmayan yöntemlere ilişkin kanıt düzeyi yüksek çalışmalara yer verilmiştir. Cerrahi hemşirelerinin gastrointestinal motiliteyi arttırmaya yönelik kanıta dayalı uygulamaları hemşirelik bakımına dahil etmeleri ve konuya ilişkin randomize kontrollü klinik çalışmaların artırılması önerilmektedir.

\section{Derleme Makale (Review Article)}

Geliș / Received: 26.06.2021 \& Kabul / Accepted: 30.07.2021

DOI: https://doi.org/10.38079/igusabder.957817

* Arş. Gör., Gazi Üniversitesi, Sağllk Bilimleri Fakültesi, Hemşirelik Bölümü, Ankara, Türkiye, E-posta: burcinirmak@gazi.edu.tr ORCID https://orcid.org/o0oo-0003-2168-1872

** Prof. Dr., Gazi Üniversitesi, Sağlık Bilimleri Fakültesi, Hemşirelik Bölümü, Ankara, Türkiye, E-posta: bhulya@gazi.edu.tr ORCID https://orcid.org/0000-0001-8241-989X 
Anahtar Kelimeler: Ameliyat sonrası dönem, gastrointestinal motilite, tamamlayıcı tıp, hemşirelik bakımı.

\title{
Use of Non-Pharmacological Methods to Increase Intestinal Functions After Abdominal Surgery: What Do Say Evidences?
}

\begin{abstract}
Today, one of the most common problems faced by patients after abdominal surgery is gastrointestinal motility dysfunction. It occurs with signs and symptoms such as inability to pass gas, lack of bowel movement, abdominal pain, distention, nausea, vomiting, constipation in patients. Failure to control these symptoms early causes additional problems in patients such as fluid-electrolyte imbalance, delayed recovery, decreased comfort, prolonged hospital stay, and increased risk of hospital-acquired infection. Both pharmacological and nonpharmacological treatment methods are used to increase intestinal motility in the postoperative period. In the literature, it is stated that non-pharmacological methods such as early mobilization, chewing gum, early oral hydration (water, warm water, tea, coffee consumption) and hot application are effective in increasing intestinal motility. These methods are preferred for reasons such as being inexpensive, easy to apply, prevent drug side effects, and have no negative effects. In this review, studies with high evidence level regarding non-pharmacological methods used to increase bowel motility of patients after abdominal surgery are included. It is recommended that surgical nurses include evidence-based practices to increase gastrointestinal motility in nursing care and increase the number of randomized controlled clinical trials on the subject.
\end{abstract}

Keywords: Postoperative period, gastrointestinal motility, complementary medicine, nursing care.

\section{Giriș}

Abdominal cerrahi sonrası hastalarda ağız kuruluğu, yutma güçlüğü, iştahsızlık, konstipasyon, diyare, bulantı, kusma, hıçkırık, gastrik dilatasyon, abdominal distansiyon, paralitik ileus gibi gastrointestinal sisteme ilişkin sorunlar görülebilmektediri-3. Erken dönemde kontrol altına alınmayan bu sorunlar hastaların iyileşme sürecinde gecikme, konforda azalma, hastanede kalma süresinde uzama gibi ilave sorunlara neden olmaktadır. 
Günümüzde kanıta dayalı uygulamalardan oluşan cerrahi sonrası hızlandırılmış iyileşme (Enhanced Recovery After Surgery; ERAS) protokollerinde yer alan "gastrointestinal motilitenin uyarılması" konusu ameliyat sonrası dönemde uygulanması gereken temel ögelerden biridir5. Bu protokollerde ameliyat sonrası dönemde ileusun önlenmesinde ameliyat sırası ve sonrasında multimodal yaklaşım önerilmektedir. Ameliyat sırasında midtorasik epidural analjezinin intravenöz opioid analjeziye, laparoskopik cerrahinin ise açık cerrahiye tercih edilmesi gerektiği bildirilmektedir. Hastalara hem ameliyat sırası hem de ameliyat sonrası dönemde aşırı sıvı yüklenmesinden kaçınılması ve ameliyat sonrası dönemde hastaların oral magnezyum oksit kullanması önerilmektedir4.

Literatürde abdominal cerrahi geçiren hastaların bağırsak motilitesini artırmak için ameliyat öncesi dönemden başlanarak gerekli önlemlerin alınması gerektiği belirtilmektedir. Hastalar ameliyat öncesi dönemde perioperatif sürece ilişkin bilgilendirilmelidir. Ameliyat sonrasında ise; erken oral hidrasyon, erken mobilizasyon, doğru sıvı tedavisinin kullanılması, prokinetik bileşiklerin uygulanması ve opioid kullanımının en aza indirilmesi gibi önlemler alınmalıdır4. Ayrıca ameliyat sonrası dönemde hastanın bağırsak hareketlerini artırmak için erken mobilizasyon, ılık su tüketimi, kahve tüketimi, çay tüketimi, sakız çiğneme, sıcak uygulama, akupunktur, akupresür, aromaterapi gibi farmakolojik olmayan yöntemler de uygulanmaktadır6.

Hemşirelik tanılarından biri olan gastrointestinal motilitede fonksiyon bozukluğu; gastrointestinal sistemde peristaltik aktivitenin artması, azalması, olmaması ya da etkisiz olması olarak tanımlanmaktadır7. Cerrahi hemşireleri ameliyat sonrası dönemde hastaların gastrointestinal motilitesini değerlendirmeli, uygun girişimde bulunmalı ve girişim sonrası yeniden değerlendirme yapılmalıdır. Literatürde ameliyat sonrası dönemde hastaların gastrointestinal motilitesini değerlendirmek amacıyla bağırsak sesleri abdomenin dört kadranından, her kadranda en az bir dakika süreyle ve stetoskop aracılığıyla dinlenmesi, oskültasyon sonrasında bağırsak sesinin özellikleri (var/yok, artmış/azalmış, hipoaktif/hiperaktif gibi) ve sıklı̆̆ının hemşireler tarafından kaydedilmesi gerektiği belirtilmektedir ${ }^{8}$.

Bu derlemede, abdominal cerrahi sonrasında hastaların bağırsak motilitesini arttırmada kullanılan farmakolojik olmayan yöntemlere ilişkin son 10 yılda (Ocak 2011-Mayıs 2021) yayınlanan ve kanıt düzeyi yüksek çalışmaların (randomize kontrollü klinik araştırmalar, sistematik derleme, meta analiz) gözden geçirilmesi amaçlanmıştır. Derlemede 
farmakolojik olmayan yöntemler; erken mobilizasyon, su tüketimi, kahve tüketimi, sakız çiğneme ve sıcak uygulama başlıkları altında incelenmiştir.

\section{Erken Mobilizasyon}

Hızlı iyileşme protokollerinin önemli bir parçası ve bağırsak hareketlerinin erken dönemde başlamasında etkili olan yöntemlerden biri erken mobilizasyondur ${ }^{4}$. Hastalar ameliyat sonrası dönemde ağrı, bulantı, baş dönmesi, yorgunluk, kendini iyi hissetmeme, komplikasyon gelişimi, intravenöz sıvı alımının devam etmesi, üriner kateter gibi yardımcı ekipman kullanımı gibi nedenlerle mobilizasyon sorunu yaşayabilir ${ }^{9-12}$. Jinekolojik cerrahi geçiren hastalarla yapılan randomize kontrollü bir çalışmada, hastaların \%12'sinin ameliyat sonrası dönemde mobilizasyon için teşvik edilemediği belirlenmiştir ${ }^{11}$. Gastrointestinal sistem cerrahisi geçiren hastalarla $(n=718)$ yapılan bir çalışmada hastaların \%55’inin ameliyat sonrası 1. günde, \%31'inin ameliyat sonrası 2. günde, diğerlerinin ise 3. gün ya da daha sonraki günlerde mobilize olduğu saptanmıştı1 ${ }^{12}$. Ameliyat sonrası dönemde mobilizasyon süresinde gecikme hastalarda solunum sistemi sorunları, venöz tromboemboli riski, insülin direncinde artma, kas kaybında artma, kas gücünde azalma, doku oksijenasyonunda azalma, düşme riski, basınç yaralanması riski ve abdominal distansiyon gibi sorunlara neden olmaktadır 4,13,14 . ERAS protokollerine göre, hastalar ameliyat günü en az iki saat ve taburcu olana kadar günde en az altı saat yatak dışında aktivite gerçekleştirmelidir4,9. Abdominal drenler ve idrar kateterleri mobilizasyonu engelleyeceğinden mümkün olduğunca kullanımından kaçınılmalıdır ${ }^{4}$. Literatürdeki erken mobilizasyona ilişkin çalışmalara bakıldığında, ilk mobilizasyon zamanı, sıklığı, uygulama protokolü, mobilizasyonun değerlendirilmesinde farklı ölçüm araçlarının kullanımı (adımsayar, giyilebilir teknolojiler, metre cinsinden yürüyüş mesafe hedefi belirlenmesi, yürüyüş çizelgesi kullanımı) gibi birçok konuda farklılıklar bulunduğu, standart bir yöntem izlenmediği görülmektedir. Randomize kontrollü bir klinik çalışmada hastaların abdominal cerrahi sonrasında iki saat içerisinde mobilize edildiği bildirilmektedir ${ }^{15}$. Endonezya'da sezaryen sonrası ilk mobilizasyonu 4. saatte sağlanan kadınların $(n=36)$ kontrol grubuna $(n=36)$ göre bağırsak hareketlerinin daha fazla olduğu saptanmıştır ${ }^{16}$. Kolon kanseri nedeniyle kolektomi ameliyatı yapılan hastalarda ameliyat sonrası egzersizin bağırsak fonksiyonlarına etkisinin incelendiği randomize kontrollü bir çalışmada, deney grubunun $(n=17)$ kontrol grubuna $(n=14)$ göre ilk gaz çıkarma süresi daha erken ve 
hastanede yatış süresi daha kısa olarak bulunmuştur. Sezaryen sonrası erken mobilizasyonun ilk bağırsak hareketi, ilk gaz çıkarma ve ilk defekasyon süresini kısaltması nedeniyle olumlu etkilerinin olduğunu belirtilmektedir ${ }^{17}$.

Ameliyat öncesi dönemde hastanın erken mobilizasyona ilişkin bilgilendirilmesi, hastaya özel bakım planı geliştirilmesi, mobilizasyon için günlük hedeflerin belirlenmesi ve hastanın yatak dışı aktiviteleri için bir hasta günlüğünün oluşturulması önerilmektedir4 Cerrahi kliniklerinde erken mobilizasyon protokollerinin geliştirilerek hekim, fizyoterapist ve hemşireler tarafından işbirliği içerisinde uygulanması hasta bakım sonuçlarını olumlu yönde etkileyecektirio,13,15.

\section{Su Tüketimi}

Ameliyat sonrası erken oral hidrasyon gastrointestinal sistem üzerine olumlu etkilerinin olması nedeniyle önerilmektedir ${ }^{18,19}$. Hastaların ameliyat sonrası dönemde ağız yoluyla aldığı ilk besin genellikle su olmaktadır3,5. Laparoskopik kolesistektomi ameliyatı olan hastalarla ayılma ünitesinde yürütülen randomize kontrollü klinik araştırmada; bilinci açık, yaşamsal bulguları stabil, kas gücü tam, öksürük ve yutma refleksi olan deney grubundaki hastalara $(\mathrm{n}=867) 3 \mathrm{ml} / \mathrm{kg}$ ile sınırlı olmak üzere su içirilmiştir. Kontrol grubundaki hastalara $(n=868)$ ise ameliyat sonrası ilk dört saatte oral hidrasyon uygulanmamıştır. Çalışmada hastaların laparoskopik cerrahi sonrasında erken oral hidrasyonu iyi tolere ettikleri ve uygulamanın hastalar için güvenli olduğu belirtilmiştir ${ }^{18}$. Laparoskopik kolesistektomi ameliyatı olan hastalarla yürütülen randomize kontrollü bir başka çalışmada, deney grubuna $(n=30)$ ameliyat sonrası 4 . saatte $200 \mathrm{ml}$ llık su verilirken, kontrol grubuna $(\mathrm{n}=30)$ ameliyat sonrası 8. saatte oral beslenme başlanmıştır. Ameliyat sonrası erken dönemde ılık su tüketiminin hastalarda ilk gaz çıkarma, defekasyona çıkma ve hastanede kalma süresini kısalttı̆̆ belirlenmiştiri19. Bir diğer randomize kontrollü çalışmada, abdominal jinekolojik cerrahi sonrasında hastalara ameliyat sonrası 2. ve 4. saatler arasında 45-50 ml su, sonrasinda her saat $100 \mathrm{ml} \mathrm{su}$, bağırsak sesi ile gaz çıkımı olduğunda serbest sıvı tüketimi şeklinde erken oral hidrasyon prosedürü uygulanmıştır. Multimodal yaklaşımlar içerisinde erken oral hidrasyonun olmasının hastalarda ileusun önlenmesinde, konforun artmasında ve hastanede kalış süresinin kısalmasında etkili olduğu saptanmıştır ${ }^{17}$. Çin'de yapılan randomize kontrollü bir çalışmada ise kolorektal cerrahi sonrasında deney grubundaki

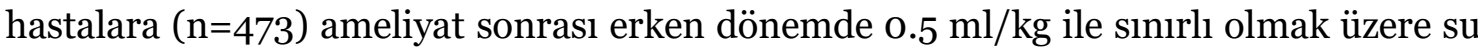


içirilmiştir. Diğer çalışmalardan farklı olarak erken oral hidrasyonun deney grubu ile kontrol grubu ( $n=500)$ arasında bağırsak hareketlerini başlatma süresi yönünden fark olmadığı belirlenmiştir ${ }^{20}$. Tayland'da yapılan bir araştırmada jinekolojik cerrahi geçiren kadın hastaların ameliyat sonrası sabah erken mobilizasyonu sağlanarak bir gruba $(\mathrm{n}=45) 120 \mathrm{ml}$ llık su, diğer gruba $(\mathrm{n}=45)$ ise aynı miktarda çay (Cassia alata Linn) içirilmiştir. Çay tüketen grupta ilk bağırsak hareketi süresi ve ilk defekasyona çıkış süresi ılık su tüketen gruba göre daha kısa olup, gruplar arasında ileus semptomları ve katı gıdaya geçiş süresi yönünden fark saptanmamıştır²1.

\section{Kahve Tüketimi}

Literatürde kahve tüketiminin bağırsak hareketleri üzerine etkilerinin incelendiği çalışmalara 1990'lı yıllardan itibaren rastlanmaktadır. Sağlıklı bireylerle yapılan bu çalışmalarda kafeinli kahve tüketiminin bağırsak hareketlerini erken sürede uyarmada etkili olduğu bildirilmektedir²2,23. Son 10 yılda ise ameliyat sonrası dönemde hastaların kahve tüketiminin bağırsak fonksiyonları üzerine etkilerinin incelendiği randomize kontrollü klinik araştırmaların arttığı belirlenmiştir. Bu çalışmalar kolorektal cerrahi ${ }^{24-}$ 28, jinekolojik cerrahi29,30 geçiren hastalarla ve sezaryan31-34 olan kadınlarla yürütülmüştür.

Literatürde kolorektal cerrahi geçiren hastalarla yürütülen çalışmalar incelendiğinde; elektif kolektomi sonrası deney grubuna $(n=40)$ ameliyat sonrası sabahtan itibaren günde $3 \mathrm{kez} 100 \mathrm{ml}$ miktarda, sütsüz, şekersiz kahve ve kontrol grubuna (n=40) aynı miktarda su verilmiştir. Araştırma sonucunda kahve tüketen hastalarda ilk bağırsak hareketi süresi, katı diyete tolerans ve ilk gaz çıkışı süresi daha erken belirlenmiştir ${ }^{28}$. Bir başka çalışmada aynı hasta grubuna, aynı sıklık ve miktarda kafeinli kahve $(n=30)$, kafeinsiz kahve $(n=30)$ ve su $(n=30)$ verilmiştir. Ameliyat sonrası bağırsak hareketleri sırasıyla kafeinsiz kahve, kafeinli kahve ve su tüketen grupta başlamıştır ${ }^{27}$. Laparoskopik ventral rektopeksi ameliyatı sonrası 5. saatte ve ameliyat sonrası günden ilk dışkılamaya kadar günde üç kez ve $100 \mathrm{ml}$ miktarda kahve $(\mathrm{n}=23)$ ve 1 lık su $(\mathrm{n}=23)$ tüketen hastalarda kahve grubunun ilk gaz çıkışı ve ilk defekasyon süresinin daha erken olduğu belirlenmiştir ${ }^{24}$. Kolorektal cerrahi geçiren hastalarda çay $(n=30)$ ve kahvenin $(n=28)$ ameliyat sonrası gün üç kez ve $100 \mathrm{ml}$ miktarda verildiği bir başka çalışmada ise kahve grubunda ilk defekasyon süresinin daha erken ve hastanede kalma süresi daha kısa olduğu saptanmıştır. Ayrıca ameliyat sonrası dönemde komplikasyon görülme oranı çay 
grubunda $(\% 36,67)$ kahve grubuna $(\% 14,29)$ göre daha fazladır ${ }^{26}$. Bu sonuçlara benzer olarak, elektif laparoskopik kolorektal rezeksiyon sonrası hastaların günde üç kez ve 150 ml miktarda çay $(n=59)$ ve kahve $(n=56)$ tükettiği çalışmada kahve grubunun ilk bağırsak hareketleri daha erken sürede başlamış ve hastanede kalma süresi daha kısa bulunmuştur. Gruplar arasında minör/majör komplikasyon gelişme durumu yönünden ise istatistiksel olarak anlamlı fark saptanmamıştır ${ }^{25}$.

Ülkemizde yapılan jinekolojik cerrahi sonrası kahve tüketiminin bağırsak hareketliliğine etkisinin incelendiği bir araştırmada deney grubuna $(n=58)$ ameliyat sonrası gün başlanarak, günde üç kez $150 \mathrm{ml}$ kafeinli kahve verilmiştir. Kontrol grubuna $(n=56)$ ise rutin klinik bakım verilmiştir. Araştırma sonucunda kahve tüketen hastalarda ilk gaz çıkışı, ilk defekasyon, ilk bağırsak hareketi ve katı diyete tolerans süresinin daha erken olduğu belirlenmiştir. Hafif ileus semptomları kontrol grubunda \%30,4 iken kahve grubunda \%10,3'tür ${ }^{29}$. Benzer hasta grubuyla aynı uygulama prosedürüyle yapılan bir başka çalışmada kahve tüketen hastalarda $(n=49)$ llık su tüketenlere $(n=47)$ göre ilk gaz çıkışı, ilk defekasyon, ilk bağırsak hareketi ve katı diyete tolerans süresinin daha erken olduğu belirlenmiştir. Postoperatif ileus oranı ise ılık su grubunda \% 14,9 ve kahve grubunda \%2 olarak saptanmıştır ${ }^{30}$.

Literatürde spinal anestezi altında sezaryen doğum yapan kadınlarla yürütülen çalışmalarda kahve tüketiminin bağırsak fonksiyonlarını hızlandırmada olumlu etkilerinin olduğu belirlenmiştir31-34. Bu çalışmalarda hastalara kahve verilme sıklı̆̆ günde üç kez olup miktarı $100 \mathrm{ml}$ olarak düzenlenmiştir. Ancak çalışmalarda hastaların erken oral hidrasyona başlama süreleri birbirinden farklı olup ameliyat sonrası 2. saatte ${ }^{31,33,34}$ ya da 8 . saatte başlandığı saptanmıştır32.

Literatürden altı randomize kontrollü çalışmanın dahil edildiği ${ }^{26-29,31,32}$ bir sistematik derleme ve meta-analiz çalışmasında kahvenin ilk gaz çıkarma süresini kısalttığı, hastanede kalma süresini etkilemediği ve ameliyat sonrası 2. saatten itibaren verilebileceği bildirilmektedir35. Bir başka meta analiz çalışmasında 341 hastanın kahve tüketiminin ilk bağırsak hareketi süresi, ilk gaz çıkışı süresi ve katı diyete tolerans süresini azalttı̆̆ı saptanmıştır. Hastaların hiçbirinde kahve tüketimine bağlı komplikasyon gelişmemiştir. Ancak mevcut çalışma sonuçlarından laksatif kullanımı, nazogastrik tüpün yeniden yerleştirilmesi gerekliliği ve yeniden ameliyat olma konularında yeterli kanıt elde edilememiştir36. 606 hastanın sonuçlarının dahil edildiği 
bir sistematik derleme ve meta-analiz çalışmasında ise kahve tüketiminin kolorektal ve jinekolojik cerrahi sonrası ilk defekasyon süresini azalttığı ancak sezaryen üzerinde etkili olmadığı bildirilmektedir37. Yapılan sistematik derleme ve meta-analizlerde çalışmaların bias riskinin orta ve yüksek olması nedeniyle kahve tüketiminin ileus üzerine etkisine yönelik kanıt düzeyinin düşük ve orta düzey olduğu belirtilmiştir37,38.

Kahve tüketimi kolay tolere edilmesi, ucuz olması, kolay bulunabilmesi ve uygulanabilmesi nedeniyle önerilmektedir. Yapılan çalışmalarda kahve tüketiminin olumsuz etkisi bildirilmemiş olup olumlu etkileri nedeniyle ameliyat sonrası dönemde tüketimi önerilmektedir ${ }^{29,36,38}$. Ancak konuyla ilgili yapılan çalışmalarda, hastaların kahve/kafein tüketim miktarının standart olmaması, hastaların ilave analjezik ve antiemetik gereksinimleri gibi parametrelerin değerlendirilmemesi gibi bazı sinırlılıklar yer almaktadır. Konuyla ilgili yeterli kanıt olmaması nedeniyle kahve içmenin bağırsak hareketleri üzerinde etkilerinin değerlendirilmesine ilişkin yeni çalışmalara gereksinim vardır ${ }^{36}$.

\section{Sakız Çiğneme}

Sakız çiğneme, sefalik-vagal stimülasyon yoluyla gastrointestinal motiliteyi uyaran bir beslenme türüdür. Abdominal cerrahi sonrasında kolay tolere edilebilmesi, ekonomik ve güvenilir olması nedeniyle gastrointestinal motiliteyi arttırmak için tercih edilmektedir ${ }^{39}$. ERAS protokollerinde yer alan multimodal yaklaşımlardan biri olmasına rağmen, ameliyat sonrası dönemde klinikte rutin sakız çiğnemeyi destekleyen araştırmaların sistematik derleme ve meta-analiz çalışmalarında düşük kanıt düzeyinde olduğu saptanmıştır39,40. Kolorektal cerrahi sonrasında ileusu iyileştirmede şekersiz sakızın şekerli sakıza göre daha etkili olduğu belirtilmektedir. Araştırmalarda uygulama prosedürleri farklı olmakla beraber genellikle günde en az üç kez 5-15 dakika sakız çiğnemenin bağırsak hareketlerini artırmada etkili olduğu bildirilmektedir39. Buna karşın, Hollanda'da 12 hastanede yürütülen randomize kontrollü çalışmada, abdominal cerrahi sonrasında deney grubundaki hastalara $(n=1000)$ günde üç kez 30 dakika süreyle sakız çiğnetilmiştir. Deney ve kontrol grubu $(\mathrm{n}=1000)$ arasında ameliyat sonrasında hastanede kalma, ilk gaz çlkarma, ilk defekasyon süresi ve 30 gün içerisinde komplikasyon gelişme durumu arasında anlamlı fark bulunmamıştır ${ }^{41}$. 


\section{Sicak Uygulama}

Literatürde konstipasyon sorunu olan erişkin bireylere abdominal ve lomber alana uygulanan sıcak paketlerin bağırsak seslerini ve dışkılama sıklığını artırdığı bildirilmektedir42. Abdominal cerrahi geçiren hastalara yapılan sıcak uygulamanın ameliyat sonrası dönemde bağırsak fonksiyonları üzerine etkisinin incelendiği randomize kontrollü klinik çalışmalar sınırlı olup43-47 konuya ilişkin sistematik derleme ve meta-analiz çalışmasına rastlanmamıştır.

Abdominal cerrahi geçiren hastalarda sıcak uygulamanın bağırsak hareketleri üzerine etkisini belirlemek amacıyla geliştirilen bir randomize kontrollü çalışma protokolünde; sıcak kompres uygulamasının ameliyat sonrası birinci günden başlanarak ilk defekasyon süresine kadar ve günde iki kez (saat 9:00-16:0o) uygulanması planlanmıştır44. Çin’de laparoskopik kolorektal cerrahi geçiren hastalarla yürütülen bir randomize kontrollü klinik çalışmada deney grubuna $(n=57)$ Shangqiu akupunktur noktasına (iç topuk kemiğinin üzerinde) sıcak kompres uygulanmış ve kontrol grubuna (n=57) rutin tedavi uygulanmıştır45. Çalışmada deney grubunda ilk bağırsak hareketi ve ilk defekasyon süresinin daha erken ve gruplar arasındaki fark istatistiksel olarak anlamlı olduğu saptanmıştır. Ancak deney grubunda ilk gaz çıkarma süresi daha erken olmasına rağmen gruplar arasındaki fark istatistiksel olarak anlamlı değildir. Çift kör randomize kontrollü bir klinik çalışmada, safra kanalı taşı nedeniyle (açık/kapalı yöntemle) ameliyat olan hastalarda ameliyat sonrası dönemde bağırsak fonksiyonunun hızlandırmak amacıyla Geleneksel Çin Tıbbı bitkileri kombinasyonu (manolya, kimyon, turp gibi) göbek çevresine sıcak kompresyon şeklinde uygulanmıştır. Deney grubuna $(\mathrm{n}=90)$ yaklaşık 300 gram ağırlı̆̆ındaki sıcak kompres gaz çıkışı olana kadar altı saatte bir yenilenerek uygulanmıştır. Plasebo grubuna $(\mathrm{n}=90)$ ise aynı miktarda tuz konularak uygulama yapılmıştır. Plasebo grubuyla karşılaştırıldığında, deney grubundaki hastaların bağırsak sesi süresi, ilk gaz çıkarma süresi ve ilk defekasyon süresi daha kısa olup, gruplar arasındaki fark istatistiksel olarak anlamlı bulunmuştur47.

Ülkemizde yapılan randomize kontrollü bir araştırmada jinekolojik cerrahi geçiren hastalara ameliyat sonrası ilk gün başlanarak, günde iki kez (sabah ve akşam) ve 10 dakika süreyle lomber bölgeye sıcak uygulama yapılmıştır. Araştırmada sıcak su torbası iki tane havluya sarılmış ve suyun $ı$ sısı $55 \pm 2^{\circ} \mathrm{C}$ olarak ayarlanmıştır. Hastaların ilk gaz çıkmasına kadar devam eden sıcak uygulamanın ilk gaz/gaita çıkarma ve oral alım 
süreleri üzerine anlamlı bir etkisi olmadığı ancak sıcak uygulama sayısı arttıkça gaz çıkarma süresinin kısaldığı saptanmıştır43. Bir başka çalışmada ise sezaryen doğum sonrası 3. saatte sıcak su ayak banyosu uygulamasının kadınların gaz çıkarma süresini etkilemediği, ancak gaz çıkarma süresini kontrol grubuna göre daha kısalttı̆̆ı belirlenmiştir ${ }^{46}$.

\section{Sonuç ve Öneriler}

Bu makalede perioperatif dönemde hasta bakımını sağlayan cerrahi hemşireleri başta olmak üzere, tüm sağlık profesyonellerine güncel literatürde yer alan kanıt düzeyi yüksek araştırma sonuçları sunulmuştur. Abdominal cerrahi sonrasında gelişebilecek sorunları önlemeye yönelik erken dönemden itibaren bazı önlemlerin alınması önemlidir. Ameliyat sonrası dönemde gastrointestinal motiliteyi arttırmada erken mobilizasyon, sakız çiğneme, ılık su içimi, kahve tüketimi, sıcak uygulama gibi farmakolojik olmayan yöntemler etkilidir ve hemşireler tarafindan da uygulanabilir. Abdominal cerrahi sonrasında bağırsak fonksiyonlarını arttırmada bir yöntem yerine birkaç farmakolojik olmayan yöntemin bir arada kullanılması, konuyla ilgili ulusal düzeyde daha detaylı çalışmaların yapılması önerilmektedir. Ayrıca konuya ilişkin randomize kontrollü klinik çalışmaların artması sistematik derleme ve meta-analiz çalışmalarına katkı vererek kanıta dayalı bilgileri artıracaktır. Güncel araştırma sonuçlarının ön plana çıkarılması hasta bakımının yeniden gözden geçirilmesine ve bu yöntemlerin klinik uygulamalara dahil edilmesine katkı sağlayacaktır.

\section{KAYNAKLAR}

1. Veličković J, Feng C, Palibrk I, Veličković D, Jovanović B, Bumbaširević V. The assessment of complications after major abdominal surgery: a comparison of two scales. J Surg Res. 2020;247:397-405. doi:10.1016/j.jss.2019.10.003.

2. İzveren AÖ, Dal Ü. Abdominal cerrahi girişim uygulanan hastalarda görülen erken dönem sorunları ve bu sorunlara yönelik hemşirelik uygulamaları. Hacettepe University Faculty of Health Sciences Nursing Journal. 2011;18(2):36-46.

3. Taşdemir N, Çelik SŞ. Hastaların cerrahi girişim sonrası abdominal distansiyona yönelik deneyimleri. Ege Üniversitesi Hemşirelik Fakültesi Dergisi. 2010; 26(3):23-31. 
4. Lassen K, Soop M, Nygren J, et al. Consensus review of optimal perioperative care in colorectal surgery: Enhanced Recovery After Surgery (ERAS) Group recommendations. Archives of Surgery. 2009;144(10):961-969. doi:10.1001/archsurg.2009.170.

5. Bozkırlı BO, Gündoğdu RH, Ersoy PE, Akbaba S, Temel H, Sayın T. ERAS protokolü kolorektal cerrahi sonuçlarımızı etkiledi mi? Ulusal Cerrahi Dergisi. 2012;28(3):149-152. doi:10.5152/UCD.2012.05.

6. Gungorduk K, Ozdemir IA. Non-pharmacological interventions for the prevention of postoperative ileus after gynecologic cancer surgery. Taiwanese Journal of Obstetrics and Gynecology. 2021;60(1):9-12. doi:10.1016/j.tjog.2020.11.002.

7. Bulechek G, Butcher H, Dochterman J, Wagner C. Hemşirelik Girişimleri Sinıflaması (NIC). Erdemir F, Kav S, Yılmaz AA, eds. 6. baskı. İstanbul: Nobel Tıp Kitabevi; 2017.

8. Uysal H. Gastrointestinal sistemin tanılaması ve fiziksel muayene. In: Enç N, ed. Sağlık Tanılaması ve Fiziksel Muayene. 1. baskı. İstanbul: Nobel Tıp Kitabevleri; 2015:71-90.

9. Gustafsson U, Scott M, Hubner M, et al. Guidelines for perioperative care in elective colorectal surgery: Enhanced Recovery After Surgery (ERAS () Society recommendations: 2018. World Journal of Surgery. 2019;43(3):659-695. doi:10.1007/so0268-018-4844-y.

10. Mathiasen MC, Andersen RM, Schmidt DS, Thomsen T, Vinther A, Danielsen AK. Early mobilisation after colorectal surgery: a qualitative study. Gastrointestinal Nursing. 2021;19(3):30-36. doi:10.12968/gasn.2021.19.3.30.

11. Liebermann M, Awad M, Dejong M, Rivard C, Sinacore J, Brubaker L. Ambulation of hospitalized gynecologic surgical patients: a randomized controlled trial. Obstet Gynecol. 2013;121(3):533-537. doi:10.1097/AOG.obo13e31828od50a.

12. Nishijima M, Baba H, Murotani K, et al. Early ambulation after general and digestive surgery: a retrospective single-center study. Langenbeck's Archives of Surgery. 2020;405(5):613-622. doi:10.1007/s00423-020-01925-9.

13. Pashikanti L, Von Ah D. Impact of early mobilization protocol on the medicalsurgical inpatient population: an integrated review of literature. Clinical Nurse Specialist. 2012;26(2):87-94.doi:10.1097/NUR.obo13e31824590e6. 
14. Vather R, Bissett I. Management of prolonged post-operative ileus: evidence-based recommendations. ANZ Journal of Surgery. 2013;83(5):319-324. doi:10.1111/ans.12102.

15. Svensson-Raskh A, Schandl AR, Ståhle A, Nygren-Bonnier M, Fagevik Olsén M. Mobilization started within 2 hours after abdominal surgery improves peripheral and arterial oxygenation: a single-center randomized controlled trial. Physical Therapy. 2021;101(5):1-11. doi:10.1093/ptj/pzabo94.

16. Herman A, Santoso B, Yunitasari E. The effect of early mobilization on intestinal peristaltics in patients after a cesarean section in Kendari City Hospital. Jurnal Ners. 2019;14(3):288-291. doi:10.20473/jn.v14i3.17148.

17. Terzioglu F, Şimsek S, Karaca K, Sariince N, Altunsoy P, Salman MC. Multimodal interventions (chewing gum, early oral hydration and early mobilisation) on the intestinal motility following abdominal gynaecologic surgery. J Clin Nurs. 2013;22(13-14):1917-1925. doi:10.1111/jocn.12172.

18. Wu M, Yang L, Zeng X, et al. Safety and feasibility of early oral hydration in the postanesthesia care unit after laparoscopic cholecystectomy: a prospective, randomized, and controlled study. Journal of PeriAnesthesia Nursing. 2019;34(2):425-430. doi:10.1016/j.jopan.2018.06.093.

19. Çaliskan N, Bulut H, Konan A. The effect of warm water intake on bowel movements in the early postoperative stage of patients having undergone laparoscopic cholecystectomy: a randomized controlled trial. Gastroenterology Nursing. 2016;39(5):340-347. doi:10.1097/SGA.0000000000000181.

20. Yin X, Yang L, Xiang S, Wu Y, Li Q. Effectiveness of early postoperative oral hydration after colorectal surgery with general anesthesia: a prospective randomized controlled trial. Research Square. https://www.researchsquare.com/article/rs-8066/v1. Yayınlanma Tarihi 25 Kasım 2019. Erişim tarihi 5 Haziran 2021. doi: 10.21203/rs.2.17432/v1

21. Phutsisen J, Kietpeerakool C, Jampathong N, et al. Effects of Cassia alata Linn on bowel function recovery following surgery for gynecological cancer: a randomized controlled trial. Complement Ther Med. 2019;47:1-5. doi:10.1016/j.ctim.2019.102222.

22. Brown S, Cann P, Read N. Effect of coffee on distal colon function. Gut. 1990;31(4):450-453. doi:10.1136/gut.31.4.450. 
23. Rao SS, Welcher K, Zimmerman B, Stumbo P. Is coffee a colonie stimulant? Eur J Gastroenterol Hepatol. 1998;10(2):113-118. doi:10.1097/00042737-19980200000003 .

24. Hayashi K, Tsunoda A, Shiraishi A, Kusanagi H. Quantification of the effects of coffee on postoperative ileus after laparoscopic ventral rectopexy: a randomized controlled trial. European Surgery. 2019;51(6):325-332.doi:10.1007/s10353-0190605-х.

25. Hasler-Gehrer S, Linecker M, Keerl A, et al. Does coffee intake reduce postoperative ileus after laparoscopic elective colorectal surgery? A prospective, randomized controlled study: the coffee study. Diseases of the Colon \& Rectum. 2019;62(8):997-1004. doi:10.1097/DCR.0000000000001405.

26. Piric M, Pasic F, Rifatbegovic Z, Konjic F. The effects of drinking coffee while recovering from colon and rectal resection surgery. Med Arh. 2015;69(6):357-361. doi:10.5455/medarh.2015.69.357-361.

27. Dulskas A, Klimovskij M, Vitkauskiene M, Samalavicius NE. Effect of coffee on the length of postoperative ileus after elective laparoscopic left-sided colectomy: a randomized, prospective single-center study. Diseases of the Colon \& Rectum. 2015;58(11):1064-1069. doi:10.1097/DCR.0000000000000449.

28. Müller SA, Rahbari N, Schneider F, et al. Randomized clinical trial on the effect of coffee on postoperative ileus following elective colectomy. British Journal of Surgery. 2012;99(11):1530-1538. doi:10.1002/bjs.8885.

29. Güngördük K, Özdemir İA, Güngördük Ö, Gülseren V, Gokçü M, Sancı M. Effects of coffee consumption on gut recovery after surgery of gynecological cancer patients: a randomized controlled trial. American Journal of Obstetrics and Gynecology. 2017;216(2):145.e1-7. doi:10.1016/j.ajog.2016.10.019.

30. Gungorduk K, Paskal EK, Demirayak G, Koseoğlu SB, Akbaba E, Ozdemir IA. Coffee consumption for recovery of intestinal function after laparoscopic gynecological surgery: a randomized controlled trial. International Journal of Surgery. 2020;82:130-135. doi:10.1016/j.ijsu.2020.08.016.

31. Goymen A, Simsek Y, Ozkaplan SE, et al. Effect of gum chewing and coffee consumption on intestinal motility in caesarean sections. J Clin Anal Med. 2017;8(5):411-415. doi:10.4328/JCAM.4901. 
32. Rabiepoor S, Yas A, Navaei J, Khalkhali HR. Does coffee affect the bowel function after caesarean section? European Journal of Obstetrics \& Gynecology and Reproductive Biology. 2018(1);220:96-99. doi:10.1016/j.ejogrb.2017.07.028.

33. Kanza Gül D, Şolt Kırca A. Effects of acupressure, gum chewing and coffee consumption on the gastrointestinal system after caesarean section under spinal anaesthesia. Journal of Obstetrics and Gynaecology. 2021;41(4):573-580. doi:10.1080/01443615.2020.1787363.

34. Koseoglu SB, Toker MK, Gokbel I, Celikkol O, Gungorduk K. Can coffee consumption be used to accelerate the recovery of bowel function after cesarean section? Randomized prospective trial. Ginekologia Polska. 2020;91(2):85-90. doi:10.5603/GP.2020.0014.

35. Kane TD, Tubog TD, Schmidt JR. The use of coffee to decrease the incidence of postoperative ileus: a systematic review and meta-analysis. Journal of PeriAnesthesia Nursing. 2020;35(2):171-177. doi:10.1016/j.jopan.2019.07.004.

36. Gkegkes ID, Minis EE, Iavazzo C. Effect of caffeine intake on postoperative ileus: a systematic review and meta-analysis. Dig Surg. 2020;37(1):22-31. doi:10.1159/000496431.

37. Cornwall HL, Edwards BA, Curran JF, Boyce S. Coffee to go? The effect of coffee on resolution of ileus following abdominal surgery: a systematic review and metaanalysis of randomised controlled trials. Clinical Nutrition. 2020;39(5):1385-1394. doi:10.1016/j.clnu.2019.06.003.

38. Eamudomkarn N, Kietpeerakool C, Kaewrudee S, Jampathong N, Ngamjarus C, Lumbiganon P. Effect of postoperative coffee consumption on gastrointestinal function after abdominal surgery: a systematic review and meta-analysis of randomized controlled trials. Scientific Reports. 2018;8(1):1-9. doi:10.1038/s41598-018-35752-2.

39. Li S, Liu Y, Peng Q, Xie L, Wang J, Qin X. Chewing gum reduces postoperative ileus following abdominal surgery: a meta-analysis of 17 randomized controlled trials. J Gastroenterol Hepatol. 2013;28(7):1122-1132. doi:10.1111/jgh.12206.

40. Short V, Herbert G, Perry R, et al. Chewing gum for postoperative recovery of gastrointestinal function. Cochrane Database of Systematic Reviews. 2015;20(2):CDoo6506. doi:10.1002/14651858.CDoo6506.pub3. 
41. de Leede EM, van Leersum NJ, Kroon HM, van Weel V, van der Sijp JRM, Bonsing BA. Multicentre randomized clinical trial of the effect of chewing gum after abdominal surgery. British journal of surgery. 2018;105(7):820-828. doi:10.1002/bjs.10828.

42. Makino Y, Choe M-A. Effects of hot packs on small-intestinal motility measured by doppler ultrasound and subjective feelings in normal adults. Gastroenterology Nursing. 2017;40(4):279-286. doi:10.1097/SGA.0000000000000222.

43. Aydın H. Jinekolojik cerrahi sonrası sakız çiğneme ve sıcak uygulamanın hastaların bağırsak fonksiyonlarına etkisinin karşılaştırılması [Yüksek Lisans Tezi]. Bursa, Türkiye: Hemşirelik Anabilim Dalı, Bursa Uludağ Üniversitesi Sağlık Bilimleri Enstitüsü;2019.

44. Cao L, Wang T, Lin J, et al. Effect of Yikou-Sizi powder hot compress on gastrointestinal functional recovery in patients after abdominal surgery: study protocol for a randomized controlled trial. Medicine. 2018;97(38):1-6. doi:10.1097/MD.0000000000012438.

45. Cao LX, Chen ZQ, Jiang Z, et al. Rapid rehabilitation technique with integrated traditional Chinese and Western medicine promotes postoperative gastrointestinal function recovery. World J Gastroenterol. 2020;26(23):3271-3282. doi:10.3748/wjg.v26.i23.3271.

46. Turan EA. Sıcak su ayak banyosunun sezaryen sonrası gaz çıkışı ve ağrıya etkisi [Doktora Tezi]. Malatya, Türkiye: Hemşirelik Anabilim Dalı, İnönü Üniversitesi Sağlık Bilimleri Enstitüsü;2020.

47. Tanab L, Huangb G, Lib X, Yina X, Wanga M, Lia J. Clinical application of combined Traditional Chinese Medicine (TCM) for warm compression of umbilical region in promoting postoperative recovery of bowel function in patients with bile duct stones. Int J Case Rep Clin Image. 2020;2(3):1-4. doi:10.36266/IJCRCI/137. 